\title{
Orbital Implants
}

\author{
Kasturi Bhattacharjee, Manab Jyoti Barman \\ and Sripurna Ghosh
}

Loss of an eye is an immense psychological setback for any patient. Providing an appropriate implant with a well fitted mobile prosthesis can go a long way to alleviate this pain. Orbital implants are medical prosthetics used to replace the lost orbital volume as well as maintain it and allow some amount of realistic movement of a prosthetic eye following enucleation (or evisceration). In 1884 implants were first described by Mules, and ever since then different implant materials, designs and shapes have been tried [1]. An orbital implant may be autologous or alloplastic, integrated, or semi- or non-integrated [2]. The shapes of the implants are usually spherical and range from 12 to $24 \mathrm{~mm}$ in diameter. The wrapping materials act as buffer to shield the conjunctiva as well as act as a conducive niche for the attachment of the extraocular muscles.

Wrapping materials may be either organic (autologous and heterologous) or alloplastic. Advantages and disadvantages of wrapping an implant and choice of wrapping material are still matter of debate among the surgeons [3]. While human donor sclera is commonly used as a readily available cost-effective

K. Bhattacharjee $(\bowtie) \cdot S$. Ghosh

Department of Orbit, Ophthalmic Plastic and Reconstructive Surgery, Sri Sankaradeva

Nethralaya, Guwahati, India

M. J. Barman

Ocular Oncology Services, Sri Sankaradeva

Nethralaya, Guwahati, India wrapping material, it entails some potential risk of disease transmission. Specially processed and marketed allografts like human donor pericardium, fascia lata, sclera, bovine pericardium, and acellular dermis have been implemented as safe alternatives with variable success rate. These materials increase the cost of surgery. Autologous materials like temporalis fascia, rectus abdominus sheath, fascia lata, etc. have also been tried as wrapping materials. However use of these autologus tissues needs a second donor operative site resulting in prolonged operation time and increased morbidity. Synthetic wrapping materials (e.g., undyed polyglactin 910 mesh) are gaining popularity due to eliminated risk of disease transmission, no need of second surgical site, simple technique, and relatively inexpensive nature.

Enucleation especially in retinoblastoma patients undergoing adjuvant radio or chemotherapy has a higher risk of long-term complication [4]. Enucleation at a young age enhances the perils of volume deficiency both in terms of bone and soft tissue [5, 6]. Hence, careful selection of implant material and meticulous surgical technique is a necessity for these patients.

Various types of implants like gold, silver, glass, silicone, cartilage, bone, fat, cork, titanium mesh, acrylics, rubber, catgut, peat, agar, silicon, hydroxyapatite, and polyethylene have been described. At present most popular integrated implants are the hydroxyapatite and polyethylene and the non-integrated being the acrylic and silicon. 


\section{Hydroxyapatite Implant}

Natural coralline hydroxyapatite material is used as the hydroxyapatite (HA) ocular implant. It contains approximately $500 \mu \mathrm{m}$ diameter pores structurally that simulate the haversian system of human bone. The microstructure of this implant allows fibrovascular ingrowth of host tissues in the anophthalmic socket [7]. Once the implant is well vascularized and integrated, it can be drilled and fitted with a motility peg implant. This motility peg is then coupled to the ocular prosthesis to enhance prosthesis motility and cosmesis.

The hydroxyapatite implant is usually wrapped in donor sclera or fascia. The socket is measured using sterile trial spheres. Usually an 18-22 $\mathrm{mm}$ implant is appropriate. Wrapping the implant adds approximately $1-1.5 \mathrm{~mm}$ to the overall diameter.

The scleral shell is cut to the appropriate size and shape to enclose the implant securely with the corneal window placed posteriorly. Multiple interrupted 6-0 Vicryl sutures are used for securely closing the sclera; $2-4 \mathrm{~mm}$ rectangular windows are cut through the sclera within $8-10 \mathrm{~mm}$ from the anterior most apex of the implant. Multiple holes are then drilled manually into the implant using a 20-gauge needle to promote further fibrovascular ingrowth at the site of each window and at the site of the posterior corneal window [8]. The four recti muscles are sutured and fixed to the anterior lip of the corresponding scleral windows. Anterior Tenon's fascia is sutured with multiple interrupted 6-0 Vicryl sutures. The conjunctiva can be closed with continuous 6-0 plain suture. Some authors report a relatively high exposure rate with hydroxyapatite compared with alloplastic sphere implants emphasizing the need for a meticulous closure in layers as well as placement of the implant posterior to the posterior tenon deep in the socket [9-12].

\section{Polyethylene (Medpor ${ }^{\oplus}$ ) Implant}

Polyethylene is a high-density straight-chain hydrocarbon material, formed by polymerization of ethylene molecules. It is nontoxic, nonaller- genic, and biocompatible. Medpor (Porex Surgical Inc., Georgia, USA) is a lightweight, polyporous form $(150-400 \mu \mathrm{m})$ of polyethylene. This material enables fibrovascular proliferation of orbital tissue allowing biointegration of the implant with the host's body, thus reduces the risk of migration, exposure and extrusion. Unlike hydroxyapatite, it is much resilient, allowing muscles to be sutured directly to it without wrapping. Many studies have reported favorable surgical outcomes after Medpor orbital implantation [13-15].

A range of implant diameters of 14-22 $\mathrm{mm}$ are available. A set of resterilizable sizer is available for measuring the appropriate implant diameter.

The classic Medpor has a rough surface with some tendency to cause erosion of overlying Tenon's capsule and conjunctiva. To compensate for this, other types of Medpor have been designed. Medpor-SST is a further refinement with a smooth, porous anterior surface, which helps minimize late-implant exposure, and the preplaced suture tunnels allow for easy anchoring of the rectus muscles. Medpor-MCOI is coneshaped, to provide extra volume in the orbit with a similar diameter implant. They have proved to be more effective in patients with phthisis bulbi or microphthalmos.

\section{Bio-ceramic Implant}

Bioceramic orbital implant is made of the porous, nonbrittle biomaterial alumina $\left(\mathrm{Al}_{2} \mathrm{O}_{3}\right)$. It has uniform interconnected pores of approximately $500 \mu \mathrm{m}$ in size. Unlike hydroxyapatite, it is manufactured with no disruption to marine ecosystems. Advantages of bio-ceramic implants include:

- Easy to manufacture, structurally strong, and free of contaminants.

- Porous, strong, and resilient composition

- Rapid fibrovascular ingrowth

- No risk of disease transmission

- Lightweight and easy manuverability during surgery

- Easy suturing of extra ocular muscles to implant

- Effortlessly hand-drilled 
- Noninflammatory, nonallergenic

- Improved motility of the artificial eye

- After implantation, a biofilm develops over the implant that acts as a barrier and helps in prevention of rejection.

\section{Self-Inflating Tissue Expanders}

Self-inflating tissue expanders are hydrogel implants which follow principle of osmotic gradient leading to volume enhancement. After implantation, absorbs body fluid and grow consistently to a predefined volume. The swelling capacity of the implant is between 7- and 12-fold, depending on the product type. These implants are indicated in the treatment of clinical anophthalmia, post enucleation socket syndrome, and congenital microphthalmia. Their advantages are as follows:

- Procedure is safe, quick, and minimally invasive

- High biocompatibility

- Lesser postoperative complications

- Optimized swelling

- Various shapes available for various indications

Being a relatively new technique, long-term safety of the material as an orbital implant has yet to be established, but early results are promising.

\section{References}

1. Mules PH. Evisceration of the globe, with artificial vitreous. Trans Ophthalmol Soc UK. 1885;5:200.

2. Baino F, Perero S, Ferraris S, Miola M, Balagna C, Verné $\mathrm{E}$, et al. Biomaterials for orbital implants and ocular prostheses: overview and future prospects. Acta Biomater. 2014;10(3):1064-87.
3. Long JA, Tann TM 3rd, Bearden WH 3rd, Callahan MA. Enucleation: is wrapping the implant necessary for optimal motility? Ophthal Plast Reconstr Surg. 2003;19(3):194-7.

4. Shildkrot Y, Kirzhner M, Haik BG, Qaddoumi I, Rodriguez-Galindo C, Wilson MW. The effect of cancer therapies on pediatric anophthalmic sockets. Ophthalmology. 2011;118(12):2480-6.

5. Hintschich C. Bony orbital development after early enucleation in humans. $\mathrm{Br} \mathrm{J}$ Ophthalmol. 2001;85(2):205-8.

6. Chojniak MM, Chojniak R, Testa ML, Min TT, Guimarães MD, Barbosa E, et al. Abnormal orbital growth in children submitted to enucleation for retinoblastoma treatment. Pediatr Hematol Oncol. 2012;34(3):102-5.

7. Perry AC. Integrated orbital implants. Adv Ophthalmic Plast Reconstr Surg. 1990;8:75-81.

8. Ferrone PJ, Dutton JJ. Rate of vascularization of coralline hydroxyapatite ocular implants. Ophthalmology. 1992;99:375-9.

9. Buettner H, Bartley GB. Tissue breakdown and exposure associated with orbital hydroxyapatite implants. Am J Ophthalmol. 1992;113:669-73.

10. Goldberg RA, Holds JB, Ebrahimpour J. Exposed hydroxyapatite orbital implants, reports of six cases. Ophthalmology. 1992;99:831-6.

11. Nunery WR, Heinz GW, Bonnin JM, et al. Exposure rate of hydroxyapatite spheres in the anophthalmic socket: histopathologic correlation and comparison with silicone sphere implants. Ophthalmic Plast Reconstr Surg. 1993;9:96-104.

12. Nunery WR, Cepela MA, Heinz GW, et al. Extrusion rate of silicone spherical anophthalmic socket implants. Ophthalmic Plast Reconstr Surg. 1993;9:90-5.

13. Baek SH. Clinical effect of porous polyethylene $\left(\right.$ Medpor $^{\circledR}$ ) orbital implant. J Korean Ophthalmol Soc. 2000;41:1858-63.

14. Blaydon SM, Shepler TR, Neuhaus RW, et al. The porous polyethylene $\left(\right.$ Medpor $^{\circledR}$ ) spherical orbital implant: a retrospective study of 136 cases. Ophthal Plast Reconstr Surg. 2003;19:364-71.

15. Kim DH, Koh YM, Na KS. Comparison of clinical results between hydroxyapatite and Medpor ${ }^{\circledR}$ orbital implant. J Korean Ophthalmol Soc. 2002;43:349-56.

Open Access This chapter is licensed under the terms of the Creative Commons Attribution 4.0 International License (http://creativecommons.org/licenses/by/4.0/), which permits use, sharing, adaptation, distribution and reproduction in any medium or format, as long as you give appropriate credit to the original author(s) and the source, provide a link to the Creative Commons license and indicate if changes were made.

The images or other third party material in this chapter are included in the chapter's Creative Commons license, unless indicated otherwise in a credit line to the material. If material is not included in the chapter's Creative Commons license and your intended use is not permitted by statutory regulation or exceeds the permitted use, you will need to obtain permission directly from the copyright holder.

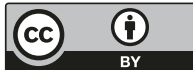

